\title{
PERFIL DE ÁCIDOS GRAXOS DE MICROALGAS CULTIVADAS COM DIÓXIDO DE CARBONO
}

\author{
Fatty acids profile of microalgae cultived with carbon dioxide
}

\author{
Michele Greque de Morais ${ }^{1}$, Jorge Alberto Vieira Costa ${ }^{2}$
}

\begin{abstract}
RESUMO
As microalgas são consideradas fontes potenciais de diversos compostos químicos. Os ácidos graxos obtidos da biomassa podem apresentar efeitos terapêuticos em humanos e podem ser usados para produção de biodiesel. Objetivou-se, neste trabalho verificar o conteúdo lipídico e o perfil dos ácidos graxos das microalgas Spirulina sp., Scenedesmus obliquus, Chlorella kessleri e Chlorella vulgaris cultivadas em diferentes concentrações de dióxido de carbono e bicarbonato de sódio. A microalga Chlorella kessleri cultivada com $12 \%$ de $\mathrm{CO}_{2}$ apresentou a maior concentração de lipídios na biomassa seca $(9,7 \%$ p/p). A máxima concentração de ácidos graxos insaturados foi $72,0 \%(\mathrm{p} / \mathrm{p})$ para $C$. vulgaris cultivada com $12 \%$ de $\mathrm{CO}_{2}$. Para os ácidos graxos saturados o maior valor encontrado foi $81,6 \%(\mathrm{p} / \mathrm{p})$, quando a microalga Spirulina sp. foi cultivada com $18 \% \mathrm{de} \mathrm{CO}_{2}$ e $16,8 \mathrm{~g} . \mathrm{L}^{-1}$ de bicarbonato de sódio.
\end{abstract}

Termos para indexação: Ácidos graxos, Chlorella, lipídios, Scenedesmus, Spirulina.

\begin{abstract}
Microalgae have a great potential as a source of several chemical compounds. The fatty acids have shown therapeutic effects and used to produce biodiesel. The aim of this work was to verify the lipid contents and the fatty acids profile of the microalga Spirulina sp., Scenedesmus obliquus, Chlorella kessleri and Chlorella vulgaris cultived in different carbon dioxide and sodium bicarbonate concentrations. The microalgae Chlorella kessleri cultived with $12 \% \mathrm{CO}_{2}$ showed the highest lipid content in the dry biomass $(9.7 \% \mathrm{p} / \mathrm{p})$. The maximum unsaturated fatty acids concentration was $72.0 \%\left(\mathrm{p} / \mathrm{p}\right.$ ) to C. vulgaris in the culture with $12 \% \mathrm{CO}_{2}$. The highest saturated fatty acids value was $81.6 \%\left(\mathrm{p} / \mathrm{p}\right.$ ) when microalga Spirulina sp. was cultived with $18 \% \mathrm{CO}_{2}$ and 16.8 g.L $\mathrm{L}^{-1}$ sodium bicarbonate.
\end{abstract}

Index terms: Chlorella, fatty acids, lipids, Scenedesmus, Spirulina.

(Recebido em 22 de junho de 2006 e aprovado em 12 de junho de 2007)

\section{INTRODUÇÃO}

As microalgas têm sido estudadas em pesquisas biotecnológicas devido a sua importância nutricional, econômica e ecológica (COSTA et al., 2006). Muitas microalgas são utilizadas para produção de alimentos por produzirem diversas substâncias, como vitaminas, sais minerais, pigmentos, lipídios e ácidos graxos. As principais aplicações dos ácidos graxos de microalgas são no enriquecimento de rações para peixes, possibilidade de uso para produção de biodiesel e fonte de ácidos graxos essenciais na dieta humana.

Elevados índices de colesterol no sangue podem conduzir a doenças coronarianas, sendo a redução deles associada ao menor consumo de ácidos graxos saturados e aumento dos ácidos graxos poliinsaturados (PUFAs) na alimentação (COZZA \& COSTA, 2000). Em adultos, o aumento do consumo de ácido 5,8,11,14,17eicosapentaenóico (EPA) tem sido associado à redução dos riscos de aterosclerose, cânceres, trombose e pressão alta (WEN \& CHEN, 2003; WILLIS et al., 1998). Anualmente, a demanda de EPA alcança 300 ton, por isso métodos como seleção de microalgas com alto redimento desse ácido graxo, melhoramento de linhagens através de manipulação genética e otimização das condições de cultivo têm sido investigados (WEN \& CHEN, 2003).

O conteúdo e a composição dos lipídios e ácidos graxos em microalgas podem ser influenciados por fatores como luz, temperatura, concentração da fonte de nitrogênio e concentração de dióxido de carbono. Illman et al. (2000) mostraram que a deficiência de nitrogênio influenciou o cultivo de Chlorella, aumentando seu conteúdo lipídico em $63 \%$. O estudo dos efeitos da adição de dióxido de carbono $\left(\mathrm{CO}_{2}\right)$, no crescimento e metabolismo de microalgas é estimulado pela necessidade de redução da emissão desse gás na atmosfera. As microalgas têm sido estudadas para biofixação de $\mathrm{CO}_{2}$ desde que foi demostrada sua capacidade de adaptação a altas concentrações desse gás,

\footnotetext{
Engenheira de Alimentos, Doutoranda - Programa de Pós-Graduação em Engenharia e Ciência de Alimentos - Fundação Universidade Federal do Rio Grande/FURG - Engenheiro Alfredo Huch, 475 - Centro - Cx. P. 475 - 96201-900 - Rio Grande, RS - migreque@yahoo.com.br

2Engenheiro de Alimentos, Doutor em Engenharia de Alimentos, Professor - Programa de Pós-Graduação em Engenharia e Ciência de Alimentos Fundação Universidade Federal do Rio Grande/FURG - Engenheiro Alfredo Huch, 475 - Centro - Cx. P. 475 - $96201-900$ - Rio Grande, RS dqmjorge@furg.br
} 
além de utilizá-lo no processo de fotossíntese. Segundo Carvalho \& Malcata (2005), a produção de ácidos graxos poliinsaturados (PUFAs) da microalga Pavlova lutheri foi otimizada combinando a intensidade da luz e a concentração de $\mathrm{CO}_{2}$.

O objetivo deste trabalho foi verificar o conteúdo lipídico e o perfil gás cromatográfico dos ácidos graxos das microalgas Scenedesmus obliquus, Chlorella vulgaris, Chlorella kessleri e Spirulina sp., cultivadas em diferentes concentrações de dióxido de carbono e bicarbonato de sódio.

\section{MATERIAL E MÉTODOS}

As microalgas Spirulina sp. LEB 18, Scenedesmus obliquus LEB 22, Chlorella vulgaris LEB 12 e Chlorella kessleri LEB 15 (MORAIS \& COSTA, 2007a,b) foram utilizadas neste estudo. Para manutenção do inóculo e cultivo foi utilizado meio Zarrouk (ZARROUK, 1966) para Spirulina sp., meio MC (WATANABE, 1960) para Scenedesmus obliquus e meio MBM (WATANABE, 1960) para Chlorella vulgaris e Chlorella kessleri. Para os ensaios com a microalga Spirulina sp. foram utilizados 2 inóculos. Um dos inóculos foi mantido em meio Zarrouk e o outro em meio Zarrouk modificado (MORAIS \& COSTA, 2007b), preparado sem fonte de carbono.

As microalgas foram cultivadas em fotobiorreatores tipo erlenmeyer de $2 \mathrm{~L}$ com volume útil 1,8L. A aeração foi realizada misturando ar comprimido ao $\mathrm{CO}_{2}$ através de um cilindro industrial (White Martins - Brasil), com vazão de $0,3 \mathrm{VVM}$ e concentrações de $\mathrm{CO}_{2}$ variando em 0,$038 ; 6,12$ e $18 \%(\mathrm{v} / \mathrm{v})$. A iluminância foi 3200 Lux fornecida por lâmpadas fluorescentes tipo luz do dia (General Eletric, 40 W). Os cultivos tiveram duração de 20 dias e concentração inicial de biomassa $0,15 \mathrm{~g} . \mathrm{L}^{-1}$. O aparato experimental foi mantido em câmara termostatizada a $30^{\circ} \mathrm{C}$, com fotoperíodo $12 \mathrm{~h}$ claro/escuro (COSTA et al., 2006).

Ao final dos cultivos, as amostras foram centrifugadas, secas em estufa a $50^{\circ} \mathrm{C}$ e moídas. Os lipídios foram extraídos de acordo com o método de Folch \& Lees (1957) e a determinação gravimétrica dos lipídios foi feita após nova secagem a $50^{\circ} \mathrm{C}$.

A esterificação dos lipídios, para obtenção dos metil-ésteres dos ácidos graxos, foi conduzida de acordo com a metodologia proposta por Metcalfe \& Schimitz (1966). A determinação de ácidos graxos foi realizada em cromatógrafo a gás modelo Varian - 3400CX, equipado com detector de ionização de chama e coluna de sílica fundida contendo fase estacionária de polietileno glicol, com $30 \mathrm{~m}$ de comprimento e $0,32 \mathrm{~mm}$ de diâmetro. $O$ gás de arraste foi nitrogênio a $0,5 \mathrm{~mL} \cdot \mathrm{min}^{-1}$. As temperaturas do injetor e do detector foram 250 e $280^{\circ} \mathrm{C}$, respectivamente. A temperatura inicial da coluna foi $100^{\circ} \mathrm{C} \mathrm{e}$, a seguir, houve aumento de $8^{\circ} \mathrm{C} \cdot \mathrm{min}^{-1}$ até $230^{\circ} \mathrm{C}$, permanecendo por $20 \mathrm{~min}$. Os ácidos graxos foram identificados pela comparação dos tempos de retenção com padrões e quantificados por normalização de áreas.

Os padrões de ácidos graxos utilizados (Sigma Supelco) foram ácido hexanóico (C6:0), ácido octanóico (C8:0), ácido decanóico (C10:0), ácido undecanóico (C11:0), ácido duodecanóico (C12:0), ácido tetradecanóico (C14:0), ácido cis-9-tetradecenóico (C14:1), ácido hexadecanóico (C16:0), ácido cis-9-hexadecenóico (C16:1), ácido heptadecanóico (C17:0), ácido 8-heptadecanóico (C17:1), ácido octadecanóico (C18:0), ácido trans-9-octadecaenóico (C18:1), ácido cis-9-octadecenóico (C18:1), ácido cis-9, trans-11-octadecaenóico (C18:2), ácido cis-9, cis-12octadecadienóoico (C18:2), ácido 9,12,15-octadecatrienóico (C18:3), ácido 6,9,12-octadecatrienóico (C18:3), ácido eicosanóico (C20:0), ácido cis-9-eicosenóico (C20:1), ácido 8,11-eicosadienóico (C20:2), ácido 5,8,11-eicosatrienóico (C20:3), ácido docosanóico (C22:0), ácido 5,8,11,14,17eicosapentanóico (C20:5), ácido cis-13-docosenóico (C22:1), ácido tetracosanóico (C24:0), ácido cis-15tetracosenóico (C24:1).

\section{RESULTADOS E DISCUSSÃO}

Na Tabela 1, apresentam-se as concentrações de lipídios, ácidos graxos insaturados (AGI), ácidos graxos poliinsaturados (PUFA) e $(\omega 3+\omega 6)$, em relação ao total dos ácidos graxos analisados (AGT) e na Tabela 2, apresenta-se o teor de ácidos graxos determinados para cada ensaio realizado com as microalgas Spirulina sp., $S$. obliquus, C. vulgaris e C. kessleri.

A C. kessleri apresentou os maiores teores lipídicos na biomassa seca comparado às demais microalgas, alcançando valores de 9,7 e 7,8\% (p/p) nos ensaios com adição de 12 e $18 \%$ de $\mathrm{CO}_{2}$, respectivamente. Para $C$. vulgaris a concentração de lipídios na biomassa seca variou de 3,0 a 4,6\% (p/p). Em cultivo de Chlorella sp. HA-1 realizado com ar enriquecido com $10 \%$ de $\mathrm{CO}_{2}$ o conteúdo lipídico alcançou 18,4\% (YANAGI et al., 1995). As microalgas apresentaram menor conteúdo lipídico nos ensaios com $0,038 \%$ de $\mathrm{CO}_{2}$, com exceção da $S$. obliquus. Essa microalga apresentou maior conteúdo lipídico (5,3\%), no ensaio com $0,038 \%$ de $\mathrm{CO}_{2}$, seguido de $4,9 \%$ no cultivo com $18 \%$ de gás.

A Spirulina sp., cultivada sem bicarbonato de sódio, apresentou maior conteúdo lipídico que a Spirulina sp. com bicarbonato e diferentes concentrações de $\mathrm{CO}_{2}$, sendo a máxima concentração de lipídios $6,1 \%$, com adição 
de $6 \% \mathrm{CO}_{2}$. A Spirulina sp., cultivada com bicarbonato de sódio, C. kessleri e C. vulgaris apresentaram o maior conteúdo lipídico nos cultivos com $12 \%$ de gás. Araújo \& Garcia (2005), observaram que o conteúdo lipídico da microalga Chaetoceros cf. wighamii não sofreu influência da adição de dióxido de carbono, entretanto Chu et al. (1996) observaram incremento na concentração lipídica, quando os cultivos foram enriquecidos com $5 \%$ (v/v) de $\mathrm{CO}_{2}$.

$\mathrm{Na}$ Tabela 2, observa-se que, nos ensaios 1 (Spirulina sp., 0,038\% de $\mathrm{CO}_{2}$, sem bicarbonato), 5 (Spirulina sp., 0,038\% de $\mathrm{CO}_{2}, 16,8$ g.L $\mathrm{L}^{-1}$ de bicarbonato), 6 (Spirulina sp., 6\% de $\mathrm{CO}_{2}, 16,8$ g.L.-1 bicarbonato), 11 (S. obliquus, $12 \%$ de $\mathrm{CO}_{2}$ ) e 12 ( $\mathrm{S}$. obliquus, $18 \%$ de $\mathrm{CO}_{2}$ ), o ácido hexadecanóico (ácido palmítico) (C16:0) foi o ácido graxo de maior concentração: 36,6; 46,4; 35,4; 37,0 e 26,3\%, respectivamente. Esses resultados foram compatíveis aos encontrados em trabalhos anteriores, onde o ácido palmítico foi determinado como predominante (COLLA et al., 2004; DESHNIUM et al., 2000; OLGUÍN et al., 2001). Segundo Makulla (2000), a microalga S. obliquus apresentou concentração de ácido palmítico (C16:0) entre 35,86 e 43,06\% e de ácido 5,8,11,14,17-eicosapentaenóico (C20:5, EPA) variando de 0 a 1,66\%. No presente estudo, essa microalga apresentou valores entre 15,3 e 37,0\% de ácido palmítico e máximo de 2,1\% para EPA. O ácido palmítico é importante fonte de energia na alimentação infantil, pois o leite materno contém de 20 a 30\% desse ácido graxo. No entanto, em adultos, ácidos graxos saturados têm sido

Tabela 1 - Concentrações (\%,p/p) de lipídios, ácidos graxos poliinsaturados (PUFA), ácidos graxos insaturados (AGI) e $(\omega 3+\omega 6)$, com relação ao total dos ácidos graxos analisados (AGT) para ensaios realizados com as microalgas Spirulina sp., S. obliquus, C. vulgaris, C. kessleri, cultivadas com diferentes concentrações de $\mathrm{CO}_{2}(\%$, v/v) e $\mathrm{NaHCO}_{3}\left(\mathrm{~g} \cdot \mathrm{L}^{-1}\right)$.

\begin{tabular}{|c|c|c|c|c|c|c|}
\hline Ensaio & $\mathrm{CO}_{2}$ & $\mathrm{NaHCO}_{3}$ & Lipídios & AGI/AGT & PUFA/AGT & $(\omega 3+\omega 6) / \mathrm{AGT}$ \\
\hline \multicolumn{7}{|c|}{ Spirulina sp. } \\
\hline 1 & 0,038 & 0,0 & 2,3 & 22,9 & 8,9 & 7,7 \\
\hline 2 & 6,0 & 0,0 & 6,1 & 40,6 & 10,4 & 10,4 \\
\hline 3 & 12,0 & 0,0 & 5,2 & 26,7 & 5,4 & 5,4 \\
\hline 4 & 18,0 & 0,0 & 3,3 & - & - & - \\
\hline 5 & 0,038 & 16,8 & 2,2 & 42,8 & * & * \\
\hline 6 & 6,0 & 16,8 & 3,5 & 26,0 & 5,2 & 5,2 \\
\hline 7 & 12,0 & 16,8 & 4,5 & 35,0 & 10,9 & 10,9 \\
\hline 8 & 18,0 & 16,8 & 3,8 & 18,4 & 15,4 & 15,4 \\
\hline \multicolumn{7}{|c|}{ Scenedesmus obliquиs } \\
\hline 9 & 0,038 & 0,0 & 5,3 & 30,5 & 8,0 & 8,0 \\
\hline 10 & 6,0 & 0,0 & 3,1 & 45,8 & 21,9 & 21,9 \\
\hline 11 & 12,0 & 0,0 & 3,3 & 50,5 & 19,2 & 19,2 \\
\hline 12 & 18,0 & 0,0 & 4,9 & 43,1 & 27,1 & 27,1 \\
\hline \multicolumn{7}{|c|}{ Chlorella kessleri } \\
\hline 13 & 0,038 & 0,0 & 4,6 & 46,8 & 29,2 & 29,2 \\
\hline 14 & 6,0 & 0,0 & 6,3 & - & - & - \\
\hline 15 & 12,0 & 0,0 & 9,7 & 36,4 & $*$ & $*$ \\
\hline 16 & 18,0 & 0,0 & 7,8 & 54,1 & 30,4 & 30,4 \\
\hline \multicolumn{7}{|c|}{ Chlorella vulgaris } \\
\hline 17 & 0,038 & 0,0 & 3,0 & 52,9 & 45,2 & 45,2 \\
\hline 18 & 6,0 & 0,0 & 3,6 & 35,7 & 31,9 & 31,9 \\
\hline 19 & 12,0 & 0,0 & 4,6 & 72,0 & 24,4 & 21,6 \\
\hline 20 & 18,0 & 0,0 & 3,0 & 68,2 & 31,3 & 31,3 \\
\hline
\end{tabular}

\footnotetext{
*: não detectado; (-): amostra não analisada.
} 
associados com o aumento do risco de doenças cardiovasculares (WILLIS et al., 1998). Em cultivo realizado por Yanagi et al. (1995) com Chlorella sp. HA-1 os ácidos graxos, em maior quantidade, foram ácido palmítico (14,2\%), ácido linoléico $(13,4 \%)$ e ácido linolênico $(26,5 \%)$.

Os ensaios 7 (Spirulina sp., $12 \%$ de $\mathrm{CO}_{2}$ e 16,8 g.L L $^{-1}$ bicarbonato), 12 (S. obliquus, $18 \%$ de $\left.\mathrm{CO}_{2}\right), 13$ (C. kessleri, 0,038\% de $\mathrm{CO}_{2}$ ), 17 (C. vulgaris, 0,038\% de $\left.\mathrm{CO}_{2}\right), 19$ (C. vulgaris, $12 \%$ de $\mathrm{CO}_{2}$ ) e 20 (C. vulgaris, $18 \%$ de $\left.\mathrm{CO}_{2}\right)$ apresentaram as maiores concentrações de ácido 6,9,12octadecatrienóico (ácido $\gamma$-linolênico, C18:3, GLA), com valores de 9,$1 ; 15,6 ; 18,9 ; 14,1 ; 14,3$ e $9,6 \%$, respectivamente. As maiores concentrações de ácido 9,12,15-octadecatrienóico (ácido $\alpha$ - linolênico, C18:3, ALA) foram 6,0 e 5,9\% nos ensaios 11 (S. obliquus, $12 \%$ de $\mathrm{CO}_{2}$ ) e 19 (C. vulgaris, $12 \%$ de $\mathrm{CO}_{2}$ ).
Em cultivos com a microalga Spirulina sp. realizados por Olguín et al. (2001) em que o meio de cultivo foi enriquecido com água do mar e dejetos de porco, a concentração de GLA alcançou $28,1 \%$. Colla et al. (2004) obtiveram $20,9 \%$ de GLA em ensaios a $30^{\circ} \mathrm{C}$ e 2,5 g. $\mathrm{L}^{-1}$ de nitrato de sódio. O GLA é utilizado no tratamento de doenças cardíacas, eczema, artrite, esclerose múltipla e tensão pré-menstrual (WARD \& SINGH, 2005). De todos ácidos graxos monoinsaturados, o ácido cis-9-octadecenóico (ácido oléico) (C18:1) foi observado em todos os ensaios, com exceção do 6 (Spirulina sp., 6\% de $\mathrm{CO}_{2}, 16,8$ g.L $\mathrm{L}^{-1}$ bicarbonato), sendo a máxima concentração obtida $37,1 \%$ no ensaio 19 (C. vulgaris, $12 \%$ de $\mathrm{CO}_{2}$ ).

Tabela 2 - Perfil gás cromatográfico das microalgas cultivadas em diferentes condições.

\begin{tabular}{|c|c|c|c|c|c|c|c|c|c|c|c|c|c|c|c|c|c|c|}
\hline AG/Ensaio & 1 & 2 & 3 & 5 & 6 & 7 & 8 & 9 & 10 & 11 & 12 & 13 & 15 & 16 & 17 & 18 & 19 & 20 \\
\hline C6:0 & $*$ & $*$ & $*$ & $*$ & 2,8 & $*$ & $*$ & $*$ & $*$ & $*$ & $*$ & $*$ & $*$ & $*$ & $*$ & $*$ & $*$ & $*$ \\
\hline C8:0 & $*$ & 1,0 & $*$ & $*$ & $*$ & $*$ & $*$ & $*$ & $*$ & $*$ & $*$ & $*$ & $*$ & $*$ & $*$ & $*$ & $*$ & $*$ \\
\hline C10:0 & $*$ & $*$ & $*$ & $*$ & 1,8 & 5,1 & 1,7 & 1,6 & 1,1 & $*$ & $*$ & $*$ & $*$ & $*$ & $*$ & $*$ & $*$ & $*$ \\
\hline C11:0 & 4,2 & $*$ & $*$ & $*$ & $*$ & $*$ & $*$ & $*$ & $*$ & $*$ & $*$ & $*$ & $*$ & $*$ & $*$ & $*$ & $*$ & $*$ \\
\hline C12:0 & 0,6 & 3,2 & 47,8 & $*$ & $*$ & $*$ & 6,2 & $*$ & $*$ & $*$ & 1,8 & $*$ & $*$ & 2,2 & $*$ & $*$ & $*$ & $*$ \\
\hline C14:0 & 2,0 & 4,0 & $*$ & $*$ & 1,4 & 18,5 & 12,8 & 10,1 & 8,2 & $*$ & $*$ & 4,3 & $*$ & 7,8 & 0,5 & $*$ & $*$ & 2,0 \\
\hline C14:1 & $*$ & $*$ & $*$ & $*$ & $*$ & 18,1 & 1,7 & 1,2 & 3,6 & $*$ & $*$ & $*$ & $*$ & 3,8 & $*$ & $*$ & $*$ & $*$ \\
\hline C16:0 & 36,6 & 4,4 & 9,4 & 46,0 & 35,4 & $*$ & 18,2 & 16,8 & 15,3 & 37,0 & 26,3 & 13,0 & 11,8 & $*$ & $*$ & 12,0 & 1,8 & 11,6 \\
\hline C16:1 & $*$ & $*$ & 13,2 & $*$ & 10,6 & 2,8 & $*$ & 1,9 & 2,9 & $*$ & $*$ & 2,5 & $*$ & $*$ & $*$ & $*$ & 0,4 & $*$ \\
\hline C17:0 & 2,8 & 33,7 & 15,9 & $*$ & $*$ & 16,9 & $*$ & 6,3 & 1,2 & $*$ & $*$ & $*$ & * & 20,6 & $*$ & 3,0 & $*$ & $*$ \\
\hline C17:1 & 1,0 & $*$ & 2,5 & $*$ & 10,2 & 1,7 & $*$ & $*$ & $*$ & 9,0 & 2,2 & $*$ & $*$ & 6,0 & $*$ & $*$ & $*$ & $*$ \\
\hline C18:0 & 20,8 & $*$ & $*$ & $*$ & 30,2 & 5,3 & 38,5 & 27,5 & 20,7 & 4,1 & 19,9 & 19,8 & 22,3 & 13,4 & 43,2 & 23,0 & 5,3 & 10,5 \\
\hline C18:1T & $*$ & 13,2 & 1,2 & 6,3 & $*$ & $*$ & $*$ & 0,9 & 1,4 & 5,5 & 3,2 & $*$ & $*$ & $*$ & 0,9 & $*$ & 0,4 & $*$ \\
\hline C18:1C & 1,2 & 8,3 & 4,3 & 32,2 & $*$ & 1,5 & 1,0 & 17,2 & 14,1 & 16,8 & 8,5 & 14,7 & 18,8 & 12,9 & 5,0 & 2,7 & 37,1 & 36,3 \\
\hline $\mathrm{C} 18: 2 \mathrm{~T}$ & 0,4 & 8,3 & 2,6 & $*$ & 0,6 & $*$ & 0,5 & 1,1 & 1,0 & 13,3 & 8,7 & 1,5 & $*$ & 2,5 & 2,8 & 2,9 & 0,6 & $*$ \\
\hline C18:2C & 0,5 & $*$ & 2,8 & $*$ & 0,7 & $*$ & $*$ & 1,3 & 10,2 & $*$ & $*$ & 4,1 & $*$ & 4,9 & 22,3 & $*$ & $*$ & 17,7 \\
\hline $\mathrm{C} 18: 3 \mathrm{G}$ & $*$ & $*$ & $*$ & $*$ & 3,8 & 9,1 & 5,4 & 3,9 & 7,3 & $*$ & 15,6 & 18,9 & $*$ & 1,3 & 14,1 & $*$ & 14,3 & 9,6 \\
\hline C18:3 & $*$ & 1,3 & $*$ & $*$ & $*$ & 1,0 & $*$ & 1,1 & 0,9 & 6,0 & 1,5 & $*$ & $*$ & $*$ & 2,9 & $*$ & 5,9 & $*$ \\
\hline C20:0 & 9,1 & $*$ & $*$ & $*$ & $*$ & 4,4 & 4,1 & 2,6 & 4,2 & $*$ & $*$ & 6,0 & $*$ & $*$ & 2,1 & 8,1 & 18,9 & 5,0 \\
\hline C20:1 & 0,8 & $*$ & $*$ & $*$ & $*$ & $*$ & $*$ & $*$ & $*$ & $*$ & $*$ & $*$ & 14,4 & $*$ & 1,6 & $*$ & 4,2 & $*$ \\
\hline C20:2 & $*$ & $*$ & $*$ & $*$ & $*$ & $*$ & $*$ & $*$ & $*$ & $*$ & $*$ & $*$ & $*$ & $*$ & $*$ & $*$ & 1,3 & $*$ \\
\hline C20:3 & 1,2 & $*$ & $*$ & $*$ & $*$ & $*$ & $*$ & $*$ & $*$ & $*$ & $*$ & $*$ & $*$ & $*$ & $*$ & $*$ & 1,4 & $*$ \\
\hline C22:0 & $*$ & 8,5 & $*$ & 7,6 & 2,0 & 14,8 & $*$ & * & 2,4 & 8,3 & 3,9 & 6,4 & $*$ & $*$ & $*$ & $*$ & 0,7 & $*$ \\
\hline C20:5 & 6,7 & $*$ & $*$ & $*$ & $*$ & 0,8 & 9,5 & $*$ & 2,1 & $*$ & $*$ & 3,9 & $*$ & 20,5 & 1,8 & $*$ & 0,3 & 3,6 \\
\hline C22:1 & 10,8 & $*$ & $*$ & $*$ & $*$ & $*$ & 0,3 & $*$ & 1,4 & $*$ & 1,4 & $*$ & $*$ & $*$ & $*$ & $*$ & 4,4 & $*$ \\
\hline C24:0 & 0,3 & $*$ & $*$ & $*$ & 0,4 & $*$ & $*$ & $*$ & $*$ & $*$ & 2,3 & 2,3 & 23,9 & $*$ & $*$ & $*$ & 0,7 & 2,3 \\
\hline C24:1 & $*$ & 6,4 & $*$ & 1,9 & $*$ & $*$ & $*$ & $*$ & $*$ & $*$ & $*$ & $*$ & $*$ & $*$ & $*$ & $*$ & $*$ & $*$ \\
\hline
\end{tabular}

AG: ácidos graxos; T: ácidos graxos trans; C: ácidos graxos cis; G: ácidos graxos gama; *: não detectado. 
A Spirulina sp. cultivada sem bicarbonato apresentou as maiores concentrações de lipídios, PUFAs, AGI e $(\omega 3+\omega 6)$ no ensaio com $6 \%$ de $\mathrm{CO}_{2}$. Para a microalga Spirulina sp., cultivada com bicarbonato, a concentração de AGI (ácidos graxos insaturados) variou entre 18,4 e 42,8\% (ensaios 8 e 5, respectivamente). Para Spirulina sp. a adição de bicarbonato (ensaios 5 a 8) levou ao incremento na concentração de PUFAs à medida que aumentou a concentração de $\mathrm{CO}_{2}$. Nesses ensaios, as concentrações de PUFA foram $0 ; 5,2 ; 10,9$ e $15,4 \%$, respectivamente.

A $S$. obliquus apresentou 8,0;21,9;19,2 e 27,1\% de PUFA nos ensaios $9\left(0,038 \%\right.$ de $\left.\mathrm{CO}_{2}\right), 10\left(6 \%\right.$ de $\left.\mathrm{CO}_{2}\right), 11$ $\left(12 \%\right.$ de $\left.\mathrm{CO}_{2}\right)$ e $12\left(18 \%\right.$ de $\left.\mathrm{CO}_{2}\right)$ respectivamente, e os AGI variaram entre 50,5 e 30,5\%. A C. kessleri apresentou 54,1\% de ácidos graxos insaturados. Essa microalga alcançou $29,2 \%$ e 30,4\% de PUFAs nos ensaios $13\left(0,038 \%\right.$ de $\left.\mathrm{CO}_{2}\right)$ e 16 ( $18 \%$ de $\left.\mathrm{CO}_{2}\right)$, respectivamente. A microalga $C$. vulgaris apresentou a maior concentração de PUFA $(45,2 \%)$, com $0,038 \%$ de $\mathrm{CO}_{2}$ (Ensaio 17) e maiores porcentagens de AGI que as demais microalgas. Segundo Sato et al. (2003), em cultivo com a microalga $C$. kessleri, as insaturações dos ácidos graxos foram mais abundantes nos ensaios com $0,04 \%$ de $\mathrm{CO}_{2}$ comparada à adição de $2 \%$ de gás.

Com exceção dos ensaios 1 (Spirulina sp., 0,038\%) e 19 (C. vulgaris, $12 \% \mathrm{CO}_{2}$ ) que apresentaram os ácidos graxos poliinsaturados 8,11-eicosadienóico (C20:2, EDA) e 5,8,11-eicosatrienóico (C20:3), nos demais ensaios os ácidos graxos poliinsaturados foram a soma de $\omega 3$ e $\omega 6$. O ensaio 17 ( $C$. vulgaris, 0,038\% de $\mathrm{CO}_{2}$ ) apresentou maior concentração de $\omega 3+\omega 6(45,2 \%)$, seguido pelas microalgas C. kessleri e $S$. obliquus que alcançaram 30,4 e 27,1\%, respectivamente. As microalgas Spirulina sp. (cultivada com bicarbonato), S. obliquus e C. kessleri apresentaram os maiores conteúdos lipídicos e $(\omega 3+\omega 6)$ nos ensaios com $18 \%$ de $\mathrm{CO}_{2}$.

Os menores valores médios de AGI (50,0\%), PUFA $(26,6 \%)$ e $(\omega 3+\omega 6)(26,0 \%)$ foram com a microalga $C$. vulgaris. A C. kessleri apresentou o maior conteúdo lipídico médio (7,1\%), comparado às demais microalgas e a Spirulina sp. apresentou as menores concentrações de lipídios, PUFA, AGI e $(\omega 3+\omega 6)$.

Os cultivos realizados com as maiores concentrações de $\mathrm{CO}_{2}(12$ e $18 \%)$ apresentaram os maiores resultados de lipídios $(5,5 \%)$, AGI $(46,0 \%)$, PUFA $(26,1 \%)$ e (w3 + w6) (26,1\%). Segundo Tsuzuki et al. (1990), o aumento da concentração de $\mathrm{CO}_{2}$ aumentou a síntese de ácidos graxos insaturados.

Os ácidos graxos saturados estavam em maior concentração que os insaturados na maioria dos ensaios, isso provavelmente tenha ocorrido pelo fato da síntese de ácidos graxos iniciar-se pelos saturados. Para a produção de biodiesel, é preferível a predominância de ácidos graxos saturados, que possuem alto número de cetano e são menos propensos à oxidação que os compostos insaturados (CANAKCI, 2007). A oxidação causa polimerização e formação de goma, evitando a combustão completa (MA \& HANNA, 1999).

As maiores concentrações de ácidos graxos trans foram $13,3 \%$ no ensaio 11 ( $\mathrm{S}$. obliquus, $12 \% \mathrm{de} \mathrm{CO}_{2}$ ), $8,3 \%$ no ensaio 2 (Spirulina sp., $6 \% \mathrm{CO}_{2}$ ) e 6,3 no ensaio 5 (Spirulina sp., 0,038\% $\mathrm{CO}_{2}, 16,8$ g.L $\mathrm{L}^{-1}$ de bicarbonato de sódio). Segundo Willis et al. (1998), os ácidos graxos trans podem prejudicar a dessaturação e a elongação do ácido linolêico e araquidônico, afetando a produção de eicosanóides. Em relação ao efeito em adultos, os ácidos graxos trans são preocupantes devido ao seu impacto nos níveis de colesterol, aumentando os níveis de LDL e reduzindo o HDL.

O ensaio 16 (C. kessleri, $18 \%$ de $\mathrm{CO}_{2}$ ) apresentou maior concentração $(20,5 \%)$ de ácido eicosapentaenóico (C20:5, EPA), seguido dos ensaios 1 (Spirulina sp., 0,038\% de $\mathrm{CO}_{2}$, e sem bicarbonato) e 8 (Spirulina sp., $18 \%$ de $\mathrm{CO}_{2}$ e $16,8 \mathrm{~g} . \mathrm{L}^{-1}$ de bicarbonato) que apresentaram 6,7 e 9,5\%, respectivamente. Segundo Hoshida et al. (2005), em cultivos com Nannochloropsis sp., o acúmulo de EPA foi incrementado pela elevação da concentração de $\mathrm{CO}_{2}$ de 0,037 a $2,0 \%$.

\section{CONCLUSÕES}

O maior conteúdo lipídico de cada microalga foi 9,7\% para C. kessleri, 6,1\% para Spirulina sp., 5,3\% para $S$. obliquus e $4,6 \%$ para $C$. vulgaris. Os resultados mostraram que, dependendo do gênero e espécie de microalga cultivada, a concentração de $\mathrm{CO}_{2}$ e a adição de bicarbonato de sódio, no meio, podem ser variadas de modo a incrementar a biossíntese de ácidos graxos saturados ou insaturados, de acordo com a utilização que se pretende dar à biomassa formada. Assim, para a produção de biodiesel, onde são desejáveis altas concentrações de ácidos graxos saturados, a microalga Spirulina sp. cultivada com $18 \%$ de $\mathrm{CO}_{2}$ e 16,8 g.L $\mathrm{L}^{-1}$ de bicarbonato de sódio apresentou $81,6 \%$ de saturados. Já para utilização da microalga na alimentação, onde altos teores de insaturados são visados, a microalga $C$. vulgaris cultivada com $12 \%$ de $\mathrm{CO}_{2}$, apresentou $72,0 \%$ de ácidos graxos insaturados.

\section{AGRADECIMENTOS}

À ELETROBRÁS - Centrais Elétricas Brasileiras S.A. e CGTEE-Companhia de Geração Térmica de Energia 
Elétrica pelo apoio financeiro para a realização desse trabalho.

\section{REFERÊNCIAS BIBLIOGRÁFICAS}

ARAÚJO, S. C.; GARCIA, V. M. T. Growth biochemical composition of the diatom Chaetoceros cf. wighamii brightwell under different temperature, salinity and carbon dioxide levels. I. Protein, carbohydrates and lipids. Aquaculture, Amsterdam, v. 246, p. 405-412, 2005.

CANAKCI, M. The potencial of restaurant waste lipids as biodiesel feedstocks. Bioresource Technology, Essex, v. 98, p. 183-190, 2007.

CARVALHO, A. P.; MALCATA, F. X. Optimization of w-3 fatty acid production by microalgae: crossover effects of $\mathrm{CO}_{2}$ and light intensity under batch and continuous cultivation modes. Marine Biotechnology, Oxford, v. 7, p. 381-388, 2005 .

CHU, W. L.; PHANG, S. M.; GOH, S. H. Environmental effects on growth and biochemical composition of Nitzschia inconspicua grunow. Journal of Applied Phytology, [S.l.], v. 8, p. 389-396, 1996.

COLLA, L. M.; BERTOLIN, T. E.; COSTA, J. A. V. Fatty acids profile of Spirulina platensis grown under different temperatures and nitrogen concentrations. Zeitschrift fur Naturforschung, Tübingen, v. 59c, p. 55-59, 2004.

COSTA, J. A. V.; MORAIS, M. G.; DALCANTON, F.; REICHERT, C. C.; DURANTE, A. J. Simultaneous cultivation of Spirulina platensis and the toxigenic cyanobacteria Microcystis aeruginosa. Zeitschrift fur Naturforschung, Tübingen, v. 61c, p. 105-110, 2006.

COZZA, K. L.; COSTA, J. A. V. Lipídios em Spirulina. Vetor, Rio Grande, v. 10, p. 69-80, 2000.

DESHNIUM, P.; PAITHOONRANGSARID, K.; SUPHATRAKUL, A.; MEESAPYODSUK, D.; TANTICHAROEN, M.; CHEEVADHANARAK, S. Temperature-independent and dependent expression of desaturase genes in filamentous cyanobacterium Spirulina platensis strain C1 (Arthospira sp. PCC 9438). FEMS Microbiology Letters, Birmingham, v. 184, p. 207-213, 2000.

FOLCH, J.; LEES, M. A simple method for isolation and purification of total lipids from animal tissues. Journal of Biological Chemistry, Bethesda, v. 226, p. 497-509, 1957.
HOSHIDA, H.; OHIRA, T.; MINEMATSU, A.; AKADA, R.; NISHIZAWA, Y. Accumulation of eicosapentaenoic acid in nannochloropsis sp. in response to elevated $\mathrm{CO}_{2}$ concentrations. Journal of Applied Phytology, [S.l.], v. 17, p. 29-34, 2005.

ILLMAN, A. M.; SCRAGG, A. H.; SHALES, S. W. Increase in Chlorella strains calorific values when in low nitrogen medium. Enzyme and Microbial Technology, Atlanta, v. 27, p. $631-635,2000$.

MA, F.; HANNA, A. Biodiesel production: a review. Bioresource Technology, Essex, v. 70, p. 1-15, 1999.

MAKULLA, A. Fatty acid composition of Scenedesmus obliquus: correlation to dilution rates. Limnology, [S.1.], v. 30 , p. $162-168,2000$.

METCALFE, L. D. A. A.; SCHIMITZ, J. R. Rapid preparation of fatty acid esters from lipids for gas liquid chromatography. Analytical Chemistry, North Carolina, v. 38, p. 510, 1966.

MORAIS, M. G.; COSTA, J. A. V. Isolation and selection of microalgae from coal fired thermoelectric power plant for biofixation of carbon dioxide. Energy Conversion Management, [S.1.], doi:10.1016/j.enconman.2006.12.011, $2007 a$.

MORAIS, M. G.; COSTA, J. A. V. Biofixation of carbon dioxide by Spirulina sp. and Scenedesmus obliquus cultived in a three-stage serial tubular photobioreactor. Journal of Biotechnology, [S.1.], doi:10.1016/ j.jbiotec.2007.01.009, 2007b.

OLGUIIN, E.; GALICIA, S.; ANGULO-GUERRERO, O.; HERNÁNDEZ, E. The effect of low light flux and nitrogen deficiency on the chemical composition of Spirulina sp. (Arthospira) gown on digested pig waste. Bioresource Technology, Essex, v. 77, p. 19-24, 2001.

SATO, N.; TSUZUKI, M.; KAWAGUCHI, A. Glycerolipid synthesis in Chlorella kessleri $11 \mathrm{~h}$ II. Effect of the $\mathrm{CO}_{2}$ concentration during growth. Biochimica et Biophysica Acta, Brunswick, v. 1633, p. 35-42, 2003.

TSUZUKI, M.; OHNUMA, E.; SATO, N.; TAKAKU, T.; KAWAGUCHI, A. Effects of $\mathrm{CO}_{2}$ concentration during growth of fatty acid composition in microalgae. Plant Physiology, Urbana, v. 93, p. 851-856, 1990. 
WARD, O. P.; SINGH, A. Omega - 3/6 fatty acids: alternative sources of production. Process Biochemistry, [S.1.], v. 40, p. 3627-3652, 2005.

WATANABE, A. List of algal strains in collection at the Institute of applied microbiology University of Tokyo. Journal of General and Applied Microbiology, London, v. 6, p. 1-4, 1960

WEN, Z. Y.; CHEN, F. Heterotrophic production of eicosapentaenoic acid by microalgae. BiotechnologyAdvances, Waterloo, v. 21, p. 273-294, 2003.
WILLIS, W. M.; LENCKI, R. E.; MARANGONI, A. G. Lipid modification strategies in the production of nutritionally functional fats and oils. Criticals Reviews in Food Science and Nutrition, Cleveland, v. 38, p. 639-674, 1998.

YANAGI, M.; WATANABE, Y.; SAIKI, H. CO fixation by Chlorella sp. HA-1 and its utilization. Energy Conversion and Management, Belton, v. 36, p. 713-716, 1995.

ZARROUK, C. Contribuition a letude dune cyanophycee: influence de divers facteurs physiques et chimiques sur la croissance et photosynthese de Spirulina maxima geitler. 1966. Thesis (Ph.D.) - University of Paris, Paris, 1966. 